\title{
Non-cooperative Pollution Control in an Inter-jurisdictional Setting
}

\author{
by \\ Robin Boadway, Queen's University, Canada \\ Zhen Song, Central University of Finance \& Economics, China \\ Jean-François Tremblay, University of Ottawa, Canada
}

October, 2012

\begin{abstract}
This paper examines various circumstances under which decentralized pollution policies can be efficient both in federal settings and in multi-region settings with labour mobility. We consider a model in which pollution control policies are set by regional governments non-cooperatively and pollution damages are borne by the residents of all regions. We characterize the efficiency of pollution policies, and of population allocation among regions, in a variety of scenarios, including when pollution policies are enacted before interregional transfers are determined by the federal government and before migration occurs; when migration decisions are taken before policy decisions; in the absence of a central government if regional governments can make voluntary interregional transfers; when decisions over pollution control policies are followed by voluntary contributions by regions to a national public good; when regions can commit to matching the abatement efforts of each other; and when regions can commit to specific levels of abatement contingent on the emissions of other regions not exceeding some maximum level.
\end{abstract}

Keywords: Decentralized pollution control, migration, interregional transfers

JEL classification: H23, H41, H79 


\section{Introduction}

Policies for controlling emissions of pollutants are sometimes enacted by subnational governments in a federation. In Canada, various provinces have implemented either carbon tax schemes or versions of cap-and-trade, more or less to the exclusion of the federal government. Similarly, in the USA, several states have engaged in carbon pricing or regulatory schemes. There may be political economy reasons for this, especially since sub-national jurisdictions - or regional governments, as we shall call them - rely to very different extents on carbon-generating industries. However, there may be reasons based on standard assignment of functions arguments for decentralizing pollution control, given that regulators and enforcers need local information about producing and consuming agents. As well, economic unions typically rely on member nations to undertake pollution control policies.

Given that pollution crosses borders freely, it is natural to assume that decentralized provision will lead to inefficiently low levels of emissions control, unless policies can be cooperatively implemented. There is, however, a literature that suggests that decentralized provision of a national public good can be efficient if regional governments are first-movers and the central government implements an optimal redistributive interregional transfer or equalization system. The literature is associated with Silva and Caplan (1997) and Caplan, Cornes and Silva (2000), and has been carefully surveyed by Akai and Sato (2008). This is the starting point for our paper.

There exist two other branches of literature that investigate circumstances under which non-cooperative behaviour can lead to efficient outcomes even when the behaviour involves the potential for free-riding. One applies to models of voluntary contribution to public goods. Guttman (1978) showed that if all agents contributing to a public good could commit to matching the contributions of others, an efficient level of contributions would result. Danziger and Schnytzer (1991) and Althammer and Buchholz (1993) showed that voluntary matching contributions may lead to a Lindahl equilibrium, and Boadway, Song and Tremblay (2007) generalized this analysis to other forms of commitment. They showed that if only one agent could commit, it could implement a scheme that would also 
be Pareto efficient. This scheme, referred to as a quantity-contingent mechanism (QCM), involves one agent committing to a contribution level contingent on a minimum level of contribution by another. Buchholz, Cornes and Rübbelke (2011) characterize the conditions under which matching equilibria are interior, Guttman and Schnytzer (1992) and Altemeyer-Bartscher, Rübbelke and Sheshinski (2010) extend the use of matching contributions to externalities, and Boadway, Song and Tremblay (2011) explore its application to international pollution control. In the latter case, when countries are able to match the abatement of each other, an efficient outcome will result, including in a multi-period setting. Boadway et al also showed that this result applies even if countries' emissions are not perfect substitutes. Buchholz, Cornes and Rübbelke (2012) consider a matching mechanism for climate protection where a subset of countries can form a coalition within which both positive and negative matching rates can emerge. This literature is for the case when there is no central (or world) government. There are other approaches that require some central coordinating agency to operate simple mechanisms for enforcing efficient regional choices, such as deposit and refund schemes proposed by Gersbach and Winkler (2007) and Gerber and Wichardt (2009).

In a federal context, fiscal decision-making can generate interregional spillovers that generally cause inefficient choices. However, efficient regional decision-making can be induced by interregional migration, as shown by Boadway (1982). Regional governments, facing an equal-utility constraint because of migration, implicitly behave in the national interest when they maximize per capita utility, a phenomenon that Myers and Papageorgiou (1993) refer to as 'incentive equivalence'. The incentive equivalence result applied mainly to the efficiency of regional fiscal decision-making when regions provide local public goods for which there is no spillover. However, even if fiscal choices are efficient, migration can be inefficient, as shown by Buchanan and Goetz (1972) and Flatters, Henderson and Mieszkowski (1974). One important rationale for federal equalization transfers is to correct this inefficiency of migration. But, as Myers (1990) shows, this inefficient migration can, in simple models, be addressed by voluntary interregional transfers without the need for a central government. Mansoorian and Myers (1993) show that this also applies with 
imperfect migration, which they model using the so-called attachment-to-home approach that is now widely used, and Wrede (1998) shows that it can apply if regional governments are not fully benevolent.

Two final bits of literature will be referred to in what follows. The first concerns the importance of the timing of decisions in a multi-government setting. Decentralized provision is shown to be efficient only if regional governments act first, followed by the central government and then private agents, the so-called 'decentralized leadership' case. Even with this order of decision-making, efficiency is prone to fail for other reasons. Regional governments will over-extend themselves if they anticipate getting bailed out by the central government, a phenomenon analysed by Goodspeed (2002), Wildasin (2004), Boadway and Tremblay (2006), and Breuillé and Vigneault (2010), among others. This is not the only timing issue that matters. Mitsui and Sato (2001) show that if migration occurs before central and regional governments make their fiscal choices, dramatic consequences can occur. The presence of regional public goods, which rewards population, combined with a redistributive federal government, which tends to equalize marginal utilities of consumption, induces households to agglomerate excessively in one or more regions.

The last relevant finding we draw on concerns the so-called neutrality theorem of voluntary contribution models of public goods. As Shibata (1971), Warr (1983) and Bergstrom, Blume and Varian (1986) have all argued, when many agents are contributing voluntarily to a public good, a redistribution of income among them will have no effect on resource allocation or welfare, at least as long as they all remain contributors after the re-allocation. Boadway and Hayashi (1999) extend this analysis to a setting in which countries are contributing to an international public good. Contributing countries' welfare will be decreasing in their populations, but the neutrality result continues to apply.

This paper draws on all these literatures. Our approach is somewhat pedagogical. We catalogue various ways in which decentralized pollution policies can lead to efficient outcomes both in federal settings and in multi-region settings in which migration is possible. We present a sequence of scenarios which share some features in common. These include a) the non-cooperative deployment of pollution control policies by regional governments when 
pollution causes damage to residents of all regions; b) the enactment of pollution policies before fiscal choices are made and, in some cases, before migration occurs; and c) the possibility of migration by households whose utility functions are identical but who may have different attachments to different regions. The models we use are highly simplified models of pollution control, whose features are only as complicated as necessary to make the point. Some of the models will be explicitly federal in the sense that there is a central government whose relevant function is to make interregional transfers. Other models will assume away federal transfers, either because they are redundant or because we want to consider economic union settings where regions are independent but where migration can occur.

The main elements of the basic model are described in the next section followed by a characterization of the social optimum. Section 4 then examines the outcome under decentralized pollution control policy when migration decisions are taken after policy decisions. In Section 5, migration decisions are viewed as the longer-run decisions. Therefore, the timing of decisions is reversed, so that migration decisions are taken before policy decisions. Section 6 looks at the case where regional governments can provide voluntary transfers to each other, after enacting their pollution control policies, while in Section 7, we let regions contribute voluntarily to a national public good in addition to controlling pollution. In Sections 8 and 9, we characterize pollution policies when one or both regions can make commitments, either to matching the emission abatement of the other region, or to achieving some level of emission abatement contingent on some maximum level of emissions for the other region. Conclusions are provided in the last section.

\section{The Basic Model}

There are two regions denoted by $i=1,2$. Region $i$ is populated with $n_{i}$ mobile residents, where $n_{1}+n_{2}=N$. In the basic model, regional production $F_{i}\left(n_{i}\right)$ is used for a clean good $x_{i}$ and a polluting good $e_{i}$, each with unit prices. (Later, we allow for public goods.) Each unit of production of good $e$ generates one unit of pollution emissions whose damages are imposed on all $N$ households according to $d\left(n_{1} e_{1}+n_{2} e_{2}\right)$, with $d^{\prime}(\cdot)>0$ and $d^{\prime \prime}(\cdot)>0$. 
The per capita benefit of emissions in region $i$ is given by $b\left(e_{i}\right)$, where $b^{\prime}\left(e_{i}\right)>0$ and $b^{\prime \prime}\left(e_{i}\right)<0$.

The mobility of individuals is limited by their degree of attachment to one of the regions. As in Mansoorian and Myers (1993), we assume that each individual is characterized by an attachment-to-region- 2 parameter $n$, uniformly distributed over $[0, N]$. Apart from their regional attachment, all individuals are identical. The utility of an individual of attachment-type $n$ is quasi-linear in $x$ and given by $u\left(x_{1}+b\left(e_{1}\right)-d\left(n_{1} e_{1}+n_{2} e_{2}\right)\right)+\alpha(N-n)$ if residing in region 1 , and by $u\left(x_{2}+b\left(e_{2}\right)-d\left(n_{1} e_{1}+n_{2} e_{2}\right)\right)+\alpha n$ if residing in region 2 , where $\alpha \in[0, \infty)$ is a parameter indicating the non-pecuniary cost of migration.

The migration equilibrium condition, assuming an interior equilibrium, is:

$$
u\left(x_{1}+b\left(e_{1}\right)-d\left(n_{1} e_{1}+n_{2} e_{2}\right)\right)+\alpha\left(N-n_{1}\right)=u\left(x_{2}+b\left(e_{2}\right)-d\left(n_{1} e_{1}+n_{2} e_{2}\right)\right)+\alpha n_{1}
$$

where $n_{1}$ is the marginal person. Households with $n \leqslant n_{1}$ reside in region 1 , so $n_{1}$ is the population in region 1 in equilibrium, and the population of region 2 is $n_{2}=N-n_{1}$.

Regions control the level of output of the polluting good in their region (by some unspecified means), while the federal government only implements interregional transfers $T_{i}$ such that $T_{1}=-T_{2}$. Of course, the federal government may do other things, but none of them are relevant for our analysis. The resource constraint in region $i$, given federal transfer $T_{i}$, is $n_{i} x_{i}+n_{i} e_{i}=F_{i}\left(n_{i}\right)+T_{i}$.

There are three decisions made in sequence in the basic model. Regional governments first choose $e_{i}$, then the federal government chooses $T_{i}$, and finally households choose their region of residence. The assumption that regions choose pollution policies before the central government chooses transfers is rationalized by the fact that pollution policies are longer-term decisions. Assuming that migration decisions are made last is the standard practice in the literature, although as shown by Mitsui and Sato (2001), reversing the order of decisions with migration decisions occurring before fiscal policy choices can affect importantly the migration equilibrium, as discussed earlier. We will consider the case where migration decisions are taken first in Section 5. There can be two sources of inefficiency: the choice of $e_{i}$ and therefore the level of nationwide damages $d(\cdot)$ imposed on all persons, 
and the choice of residence, which is made by households but is influenced by regional and federal policies.

Before examining the outcome under decentralized policy-making, we briefly characterize the socially optimal allocation.

\section{The Social Optimum}

We can characterize the social optimum by choosing the consumption of clean and polluting goods for both regions $\left(x_{i}, e_{i}\right)$, as well as the allocation of population $\left(n_{1}, n_{2}\right)$, to maximize the sum of utilities for both regions, including the sum of attachment benefits, subject to the resource constraint and the migration equilibrium condition. ${ }^{1}$ The problem is the following:

$$
\begin{gathered}
\max _{\left\{x_{i}, e_{i}, n_{1}\right\}} n_{1} u\left(x_{1}+b\left(e_{1}\right)-d\left(n_{1} e_{1}+n_{2} e_{2}\right)\right)+\alpha n_{1} N-\int_{0}^{n_{1}} \alpha n d n \\
+n_{2} u\left(x_{2}+b\left(e_{2}\right)-d\left(n_{1} e_{1}+n_{2} e_{2}\right)\right)+\int_{n_{1}}^{N} \alpha n d n
\end{gathered}
$$

subject to

$$
n_{1} x_{1}+n_{2} x_{2}+n_{1} e_{1}+n_{2} e_{2}=F_{1}\left(n_{1}\right)+F_{2}\left(n_{2}\right)
$$

and

$$
u\left(x_{1}+b\left(e_{1}\right)-d\left(n_{1} e_{1}+n_{2} e_{2}\right)\right)+\alpha\left(N-n_{1}\right)=u\left(x_{2}+b\left(e_{2}\right)-d\left(n_{1} e_{1}+n_{2} e_{2}\right)\right)+\alpha n_{1}
$$

where $\lambda$ and $\Phi$ are the Lagrange multipliers associated with each constraint and $n_{2}=$ $N-n_{1}$. The first-order conditions to this problem are:

$$
\begin{gathered}
x_{1}: \quad n_{1} u_{1}^{\prime}-\lambda n_{1}+\Phi u_{1}^{\prime}=0 \\
x_{2}: \quad n_{2} u_{2}^{\prime}-\lambda n_{2}-\Phi u_{2}^{\prime}=0 \\
e_{1}: \quad n_{1} u_{1}^{\prime}\left(b^{\prime}\left(e_{1}\right)-n_{1} d^{\prime}(\cdot)\right)-n_{1} n_{2} u_{2}^{\prime} d^{\prime}(\cdot)-\lambda n_{1}
\end{gathered}
$$

1 As is standard in federalism models, we assume the planner cannot dictate where individuals live. He must abide by a migration equilibrium condition. 


$$
\begin{gathered}
+\Phi\left(u_{1}^{\prime}\left(b^{\prime}\left(e_{1}\right)-n_{1} d^{\prime}(\cdot)\right)+n_{1} u_{2}^{\prime} d^{\prime}(\cdot)\right)=0 \\
e_{2}: \quad n_{2} u_{2}^{\prime}\left(b^{\prime}\left(e_{2}\right)-n_{2} d^{\prime}(\cdot)\right)-n_{1} n_{2} u_{1}^{\prime} d^{\prime}(\cdot)-\lambda n_{2} \\
-\Phi\left(u_{2}^{\prime}\left(b^{\prime}\left(e_{2}\right)-n_{2} d^{\prime}(\cdot)\right)+n_{2} u_{1}^{\prime} d^{\prime}(\cdot)\right)=0 \\
n_{1}: \quad u_{1}-n_{1} u_{1}^{\prime} d^{\prime}(\cdot)\left(e_{1}-e_{2}\right)+\alpha\left(1-n_{1}\right)-u_{2}-n_{2} u_{2}^{\prime} d^{\prime}(\cdot)\left(e_{1}-e_{2}\right)-\alpha n_{1} \\
+\lambda\left(F_{1}^{\prime}\left(n_{1}\right)-F_{2}^{\prime}\left(n_{2}\right)-x_{1}+x_{2}-e_{1}+e_{2}\right) \\
+\Phi\left(-u_{1}^{\prime} d^{\prime}(\cdot)\left(e_{1}-e_{2}\right)-\alpha+u_{2}^{\prime} d^{\prime}(\cdot)\left(e_{1}-e_{2}\right)-\alpha\right)=0
\end{gathered}
$$

where $u_{i}=u\left(x_{i}+b\left(e_{i}\right)-d\left(n_{1} e_{1}+n_{2} e_{2}\right)\right)$. Substituting (2) and (3) in (4) and (5) and rearranging, we obtain:

$$
b^{\prime}\left(e_{1}\right)=b^{\prime}\left(e_{2}\right)=1+N d^{\prime}(\cdot)
$$

Equation (7) indicates that, in the social optimum, the marginal benefits of emissions are equalized across regions and the level of emissions in each region is such that the marginal benefits equal the relative price of the polluting good plus the sum of marginal damages. This condition implies that $e_{1}=e_{2}$. Using (2) and (3), as well as the migration equilibrium condition and $e_{1}=e_{2}$ in equation (6), and rearranging, we can derive the following:

$$
\left(F_{1}^{\prime}\left(n_{1}\right)-x_{1}\right)-\left(F_{2}^{\prime}\left(n_{2}\right)-x_{2}\right)=\frac{2 \alpha \Phi}{\lambda}=2 \alpha \frac{n_{1} n_{2}\left(u_{2}^{\prime}-u_{1}^{\prime}\right)}{\left(n_{1}+n_{2}\right) u_{1}^{\prime} u_{2}^{\prime}}
$$

Equation (8) is the optimal migration condition.

The social optimum can be decentralized with a common price for emissions in the two regions, equal to $N d^{\prime}(\cdot)$, and an interregional transfer $T_{1}$ to induce the optimal allocation of population. To derive some intuition about optimal migration, note first that the allocation of population between the two regions that maximizes the value of attachment to home solves:

$$
\max _{n_{1}} \alpha n_{1} N-\int_{0}^{n_{1}} \alpha n d n+\int_{n_{1}}^{N} \alpha n d n
$$

This yields $n_{1}=N / 2$, so people are equally divided between the two regions. If the regions have the same production function $\left(F_{1}(n)=F_{2}(n)\right)$, it would be optimal to allocate people equally between the two regions. In this case, $x_{1}=x_{2}$ and $\Phi=0$, so the migration 
equilibrium constraint is not binding, $F_{1}^{\prime}=F_{2}^{\prime}$ and $T_{1}=0$. However, if productivity differs between the two regions, this will be an inefficient allocation, even though it maximizes the value of attachment to home. If region 1 has a superior production function $\left(F_{1}(n)>\right.$ $\left.F_{2}(n)\right)$, it is optimal to have more people there, and an incentive can be provided via $T_{1}>0$. In this case, $x_{1}>x_{2}$, so $\Phi>0$. Whenever needed in what follows, we will assume that region 1 is the more productive.

Note that with perfect labour mobility, $\alpha=0$ and the migration equilibrium condition is simply $u_{1}=u_{2}$. Therefore, $x_{1}=x_{2}$ (since all the other elements of utility are identical between regions), $F_{1}^{\prime}\left(n_{1}\right)=F_{2}^{\prime}\left(n_{2}\right)$ and $T_{1}=0$. Without migration $(\alpha$ high $), \Phi=0$, and a transfer will be required to insure that $x_{1}=x_{2}$ and $F_{1}^{\prime}=F_{2}^{\prime}$. In this case, $T_{1}>0$ if $F_{1}(n)>F_{2}(n)$.

\section{Decentralized Pollution Control}

We now turn to the decentralized policy case where we assume that pollution policies set by regional governments are longer-term decisions than federal transfers. The timing of decisions is the following: first, regions choose pollution policies $e_{i}$; the federal government then chooses transfers $T_{i}$; and finally, individuals make their migration decisions. Once pollution policies, transfers and migration decisions are made, consumption of the clean good $x_{i}$ in each region is determined by the regional resource constraint. The regional and federal government problems are solved by backward induction starting with the federal transfer policy.

\section{Federal Government Problem}

The problem of the federal government consists in choosing $T_{i}, x_{i}$ and $n_{1}\left(=N-n_{2}\right)$, taking $e_{i}$ as given, to maximize: ${ }^{2}$

$$
n_{1} u\left(x_{1}+b\left(e_{1}\right)-d\left(n_{1} e_{1}+n_{2} e_{2}\right)\right)+\alpha n_{1} N-\int_{0}^{n_{1}} \alpha n d n
$$

2 Population allocation $n_{1}$ is an artificial choice variable of the federal government, and is justified by adding the migration equilibrium constraint to the problem. An alternative is to let $n_{1}$ be determined endogenously as a function of the other control variables using the migration equilibrium condition. 


$$
+n_{2} u\left(x_{2}+b\left(e_{2}\right)-d\left(n_{1} e_{1}+n_{2} e_{2}\right)\right)+\int_{n_{1}}^{N} \alpha n d n
$$

subject to

$$
\begin{gathered}
F_{i}\left(n_{i}\right)+T_{i}=n_{i} x_{i}+n_{i} e_{i}, \quad i=1,2 \\
T_{1}+T_{2}=0 \\
u\left(x_{1}+b\left(e_{1}\right)-d(\cdot)\right)+\alpha\left(N-n_{1}\right)=u\left(x_{2}+b\left(e_{2}\right)-d(\cdot)\right)+\alpha n_{1}
\end{gathered}
$$

The first set of constraints are the resource constraints for each region, the second is the federal budget constraint, and the third is the migration equilibrium condition. We can substitute the resource constraints and the federal government budget constraint into the objective function and maximize with respect to $T_{1}$ and $n_{1}$ only. The first-order conditions are:

$$
\begin{gathered}
T_{1}: \quad u_{1}^{\prime}-u_{2}^{\prime}+\Phi \frac{u_{1}^{\prime}}{n_{1}}+\Phi \frac{u_{2}^{\prime}}{n_{2}}=0 \\
n_{1}: u_{1}+\left(n_{1}+\Phi\right) u_{1}^{\prime}\left(\frac{\left(F_{1}^{\prime}-e_{1}\right) n_{1}-\left(F_{1}\left(n_{1}\right)+T_{1}-n_{1} e_{1}\right)}{n_{1}^{2}}-d^{\prime}(\cdot)\left(e_{1}-e_{2}\right)\right) \\
+\alpha\left(N-n_{1}\right)-u_{2}+\left(n_{2}-\Phi\right) u_{2}^{\prime}\left(\frac{\left(-F_{2}^{\prime}+e_{2}\right) n_{2}+\left(F_{2}\left(n_{2}\right)-T_{1}-n_{2} e_{2}\right)}{n_{2}^{2}}\right. \\
\left.-d^{\prime}(\cdot)\left(e_{1}-e_{2}\right)\right)-\alpha n_{1}-2 \alpha \Phi=0
\end{gathered}
$$

where $\Phi$ is the Lagrange multiplier associated with the migration equilibrium condition. Using the migration equilibrium condition and (9) in (10), we can get after some manipulations:

$$
\left(F_{1}^{\prime}\left(n_{1}\right)-x_{1}\right)-\left(F_{2}^{\prime}\left(n_{2}\right)-x_{2}\right)=2 \alpha \frac{n_{1} n_{2}\left(u_{2}^{\prime}-u_{1}^{\prime}\right)}{\left(n_{1}+n_{2}\right) u_{1}^{\prime} u_{2}^{\prime}}+\left(e_{1}-e_{2}\right)\left(1+N d^{\prime}(\cdot)\right)
$$

This equation is similar to equation (8) that characterizes the allocation of population in the social optimum, but includes an additional term (the second term on the right side) whenever $e_{1} \neq e_{2}$. 


\section{Regional Government Problem}

Anticipating the federal government transfer policy, region 1 will choose its pollution control policy $e_{1}$ and (artificially) the federal transfer $T_{1}$ to maximize:

$$
u\left(\frac{F_{1}\left(n_{1}\right)+T_{1}-n_{1} e_{1}}{n_{1}}+b\left(e_{1}\right)-d\left(n_{1} e_{1}+n_{2} e_{2}\right)\right)
$$

subject to condition (11) characterizing the federal government policy derived above, which incorporates the migration equilibrium condition. An analogous problem is solved by region 2. The attachment-to-home component is left out since it does not affect the regional problems. Similarly, maximizing total utility rather than per capita utility would lead to the same solution. The first-order conditions are:

$$
\begin{gathered}
T_{1}: \quad \frac{u_{1}^{\prime}}{n_{1}}-\delta\left(\frac{1}{n_{1}}+\frac{1}{n_{2}}\right)+\left(\frac{2 \delta \alpha n_{1} n_{2}}{\left(n_{1}+n_{2}\right)\left(u_{1}^{\prime} u_{2}^{\prime}\right)^{2}}\right)\left[\left(\frac{u_{2}^{\prime \prime}}{n_{2}}+\frac{u_{1}^{\prime \prime}}{n_{1}}\right) u_{1}^{\prime} u_{2}^{\prime}\right. \\
\left.+\left(u_{2}^{\prime}-u_{1}^{\prime}\right)\left(\frac{u_{1}^{\prime \prime} u_{2}^{\prime}}{n_{1}}-\frac{u_{1}^{\prime} u_{2}^{\prime \prime}}{n_{2}}\right)\right]=0 \\
e_{1}: \quad u_{1}^{\prime}\left(-1+b^{\prime}\left(e_{1}\right)-n_{1} d^{\prime}(\cdot)\right)+\delta\left(1-\frac{2 \alpha n_{1} n_{2}}{\left(n_{1}+n_{2}\right)\left(u_{1}^{\prime} u_{2}^{\prime}\right)^{2}} .\right. \\
\quad\left[\left(-d^{\prime}(\cdot) n_{1} u_{2}^{\prime \prime}-u_{1}^{\prime \prime}\left(-1+b^{\prime}\left(e_{1}\right)-n_{1} d^{\prime}(\cdot)\right)\right) u_{1}^{\prime} u_{2}^{\prime}\right. \\
\left.-\left(u_{2}^{\prime}-u_{1}^{\prime}\right)\left(u_{1}^{\prime \prime}\left(-1+b^{\prime}\left(e_{1}\right)-n_{1} d^{\prime}(\cdot)\right) u_{2}^{\prime}-u_{1}^{\prime} u_{2}^{\prime \prime} n_{1} d^{\prime}(\cdot)\right)\right] \\
\left.-1-N d^{\prime}(\cdot)-N d^{\prime \prime}(\cdot) n_{1}\left(e_{1}-e_{2}\right)\right)=0
\end{gathered}
$$

where $\delta$ is the Lagrange multiplier associated with the constraint (11) that characterizes the policy of the federal government. Substituting (12) in (13) and rearranging, we can derive:

$$
b^{\prime}\left(e_{1}\right)=1+N d^{\prime}(\cdot)+\frac{n_{1} n_{2}\left(N u_{2}^{\prime}\right)^{2} d^{\prime \prime}(\cdot)\left(e_{1}-e_{2}\right)}{\left(N u_{2}^{\prime}\right)^{2}-2 \alpha n_{1}^{2} n_{2} u_{2}^{\prime \prime}}
$$

Solving the same problem for region 2 gives

$$
b^{\prime}\left(e_{2}\right)=1+N d^{\prime}(\cdot)-\frac{n_{1} n_{2}\left(N u_{1}^{\prime}\right)^{2} d^{\prime \prime}(\cdot)\left(e_{1}-e_{2}\right)}{\left(N u_{1}^{\prime}\right)^{2}-2 \alpha n_{1} n_{2}^{2} u_{1}^{\prime \prime}}
$$


Given that $b^{\prime}\left(e_{i}\right)>0, b^{\prime \prime}\left(e_{i}\right)<0, d^{\prime \prime}(\cdot)>0$ and $u_{i}^{\prime \prime}<0,(14)$ and (15) can only be both satisfied if $e_{1}=e_{2}$. Therefore, $b^{\prime}\left(e_{1}\right)=b^{\prime}\left(e_{2}\right)=1+N d^{\prime}(\cdot)$, as in the optimum. Using $e_{1}=e_{2}$ in (11), we immediately get equation (8) which characterizes migration in the social optimum. Therefore, both environmental efficiency and efficiency in the distribution of population are achieved. This corresponds with Caplan, Cornes and Silva (2000).

Note that decentralized pollution policies would be efficient even without labour mobility. In this case, the federal government would choose $T_{i}, x_{i}$ and $n_{1}$ to maximize $n_{1} u\left(x_{1}+b\left(e_{1}\right)-\right.$ $d(\cdot))+n_{2} u\left(x_{2}+b\left(e_{2}\right)-d(\cdot)\right)$, subject to $F_{i}\left(N_{i}\right)=n_{i} x_{i}+n_{i} e_{i}+T_{i}$, for $i=1,2$. The transfer policy that solves this problem is such that $u_{1}^{\prime}=u_{2}^{\prime}$ and $u_{1}=u_{2}$. Anticipating federal transfers, region $i$ would choose $x_{i}, e_{i}$ and $T_{i}$ to maximize $u\left(x_{i}+b\left(e_{i}\right)-d(\cdot)\right)$ subject to its resource constraint, $n_{i} x_{i}+n_{i} e_{i}=F_{i}\left(n_{i}\right)+T_{i}$, and $u\left(x_{1}+b\left(e_{1}\right)-d(\cdot)\right)=u\left(x_{2}+b\left(e_{2}\right)-d(\cdot)\right)$. Solving this problem leads to $b^{\prime}\left(e_{i}\right)=1+N d^{\prime}(\cdot)$, so efficiency is achieved.

With perfect labour mobility on the other hand, decentralized pollution policies are efficient even in the absence of federal transfers. To see this, suppose there are no federal transfers. In this case, region 1's problem is

$$
\max _{\left\{e_{1}, n_{1}\right\}} u\left(\frac{F_{1}\left(n_{1}\right)-n_{1} e_{1}}{n_{1}}+b\left(e_{1}\right)-d\left(n_{1} e_{1}+n_{2} e_{2}\right)\right)
$$

subject to

$$
u\left(\frac{F_{1}\left(n_{1}\right)-n_{1} e_{1}}{n_{1}}+b\left(e_{1}\right)-d(\cdot)\right)=u\left(\frac{F_{2}\left(n_{2}\right)-n_{2} e_{2}}{n_{2}}+b\left(e_{2}\right)-d(\cdot)\right)
$$

From the first-order condition to this problem, we obtain:

$F_{1}^{\prime}-x_{1}=\left(F_{2}^{\prime}-x_{2}\right) \frac{b_{1}^{\prime}-1-n_{1} d^{\prime}}{n_{2} d^{\prime}}+e_{1}+n_{1} d^{\prime}\left(e_{1}-e_{2}\right)-\left(e_{2}-n_{2} d^{\prime}\left(e_{1}-e_{2}\right)\right) \frac{b_{1}^{\prime}-1-n_{1} d^{\prime}}{n_{2} d^{\prime}}$

A condition analogous to the above can be obtain from the problem of region 2 . It can readily be shown that both of these conditions can only be satisfied if

$$
\frac{b_{1}^{\prime}-1-n_{1} d^{\prime}}{n_{2} d^{\prime}}=\frac{n_{1} d^{\prime}}{b_{2}^{\prime}-1-n_{2} d^{\prime}}
$$

which implies that $b^{\prime}\left(e_{1}\right)=1+\left(n_{1}+n_{2}\right) d^{\prime}=b^{\prime}\left(e_{2}\right)$, so $e_{2}=e_{1}$, and $F_{1}^{\prime}-x_{1}=F_{2}^{\prime}-x_{2}$. Pollution policies and the allocation of labour across regions correspond with the optimum 
without any need for federal transfers. In fact, we can easily show that transfers would have no effect under perfect labour mobility, which can be seen as an application of the well-known neutrality theorem (Shibata 1971; Warr 1983; Bergstrom, Blume and Varian 1986) in the current context.

Finally, it is important to note that the efficiency of decentralized policies applies only if regional governments maximize per capita utility or total utility of original residents. If governments were to maximize the total utility of final residents, there would be an incentive to set policies in order to attract residents, which would distort the efficiency of the equilibrium.

\section{Perfect Mobility with Regional Public Goods}

Let us now briefly introduce a regional public good $g_{i}$ in this setting. We assume that the public good in each region is provided at unit cost, that there is perfect labour mobility, so $\alpha=0$, and that the utility function takes the following form: $u\left(x_{i}+b\left(e_{i}\right)-d\left(n_{1} e_{1}+n_{2} e_{2}\right)+\right.$ $\left.v\left(g_{i}\right)\right)$. Without any environmental externality, regional choices of public good provision, subject to the migration equilibrium condition, will yield an efficient choice of $g_{i}$ as long as regions maximize per capita utility, as initially shown by Boadway (1982). Since perfect mobility will equalize utilities across regions, regional governments will effectively maximize utility in both regions by maximizing the per capita utility of their residents. However, the allocation of labour across regions will generally not be efficient. Transfers between regions, if determined before regional decisions are made, can be set to induce the efficient allocation of population (Boadway and Flatters, 1982). On the other hand, if transfers are determined after regional policies, regional governments will tend to over-provide regional public goods in order to elicit larger transfers from the federal government.

In the presence of an environmental externality, full efficiency is achieved without any federal transfers. In this case, the problem of region 1 is to maximize per capita utility:

$$
\max _{\left\{e_{1}, n_{1}, g_{1}\right\}} u\left(\frac{F_{1}\left(n_{1}\right)-n_{1} e_{1}-g_{1}}{n_{1}}+b\left(e_{1}\right)-d\left(n_{1} e_{1}+n_{2} e_{2}\right)+v\left(g_{1}\right)\right)
$$

subject to migration equilibrium:

$u\left(\frac{F_{1}\left(n_{1}\right)-n_{1} e_{1}-g_{1}}{n_{1}}+b\left(e_{1}\right)-d(\cdot)+v\left(g_{1}\right)\right)=u\left(\frac{F_{2}\left(n_{2}\right)-n_{2} e_{2}-g_{2}}{n_{2}}+b\left(e_{2}\right)-d(\cdot)+v\left(g_{2}\right)\right)$ 
The first-order conditions for $e_{1}$ and $n_{1}$ are analogous to those in the perfect mobility case without public goods analyzed in the previous sub-section, and lead to $b^{\prime}\left(e_{1}\right)=b^{\prime}\left(e_{2}\right)=$ $1+N d^{\prime}, e_{2}=e_{1}$, and $F_{1}^{\prime}-x_{1}=F_{2}^{\prime}-x_{2}$. From the first-order condition for $g_{1}$, we immediately obtain $n_{1} v^{\prime}\left(g_{1}\right)=1$, so the Samuelson condition for efficient provision of $g_{1}$ is satisfied. Federal transfers are unnecessary, in this case.

If federal transfers are provided ex post however, public goods provision will be distorted. To see this, we start by characterizing the federal transfer policy (chosen after $e_{i}$ and $g_{i}$ ). The problem is:

$$
\max _{\left\{T_{1}, n_{1}\right\}} n_{1} u\left(x_{1}+b\left(e_{1}\right)-d\left(n_{1} e_{1}+n_{2} e_{2}\right)+v\left(g_{1}\right)\right)+n_{2} u\left(x_{2}+b\left(e_{2}\right)-d\left(n_{1} e_{1}+n_{2} e_{2}\right)+v\left(g_{2}\right)\right)
$$

subject to the resource constraint of each region, the federal budget constraint and the migration equilibrium condition:

$$
\begin{gathered}
F_{i}\left(n_{i}\right)+T_{i}=n_{i} x_{i}+n_{i} e_{i}+g_{i}, \quad i=1,2 \\
T_{1}+T_{2}=0 \\
u\left(x_{1}+b\left(e_{1}\right)-d(\cdot)+v\left(g_{1}\right)\right)=u\left(x_{2}+b\left(e_{2}\right)-d(\cdot)+v\left(g_{2}\right)\right)
\end{gathered}
$$

The first-order conditions with respect to $T_{1}$ and $n_{1}$ (after having substituted the resource constraints and the federal government budget constraint into the objective function) are (9) and:

$$
\begin{gathered}
u_{1}+\left(n_{1}+\Phi\right) u_{1}^{\prime}\left(\frac{\left(F_{1}^{\prime}-e_{1}\right) n_{1}-\left(F_{1}\left(n_{1}\right)+T_{1}-n_{1} e_{1}-g_{1}\right)}{n_{1}^{2}}-d^{\prime}(\cdot)\left(e_{1}-e_{2}\right)\right) \\
-u_{2}+\left(n_{2}-\Phi\right) u_{2}^{\prime}\left(\frac{\left(-F_{2}^{\prime}+e_{2}\right) n_{2}+\left(F_{2}\left(n_{2}\right)-T_{1}-n_{2} e_{2}-g_{2}\right)}{n_{2}^{2}}-d^{\prime}(\cdot)\left(e_{1}-e_{2}\right)\right)=0
\end{gathered}
$$

Using (9) and the migration equilibrium condition, $u_{1}=u_{2}$, in (16), and rearranging, we obtain:

$$
\left(F_{1}^{\prime}\left(n_{1}\right)-x_{1}\right)-\left(F_{2}^{\prime}\left(n_{2}\right)-x_{2}\right)=\left(e_{1}-e_{2}\right)\left(1+N d^{\prime}(\cdot)\right)
$$

Regional governments will anticipate how their pollution policies as well as their level of public good provision will affect federal transfers. The problem of region 1 is:

$$
\max _{\left\{e_{1}, g_{1}, T_{1}\right\}} u\left(\frac{F_{1}\left(n_{1}\right)+T_{1}-n_{1} e_{1}-g_{1}}{n_{1}}+b\left(e_{1}\right)-d\left(n_{1} e_{1}+n_{2} e_{2}\right)+v\left(g_{1}\right)\right)
$$


subject to (17). The first-order conditions are:

$$
\begin{gathered}
e_{1}: \quad u_{1}^{\prime}\left(-1+b^{\prime}\left(e_{1}\right)-n_{1} d^{\prime}(\cdot)\right)+\delta\left(-N d^{\prime}(\cdot)-N d^{\prime \prime}(\cdot) n_{1}\left(e_{1}-e_{2}\right)\right)=0 \\
g_{1}: \quad u_{1}^{\prime}\left(\frac{-1}{n_{1}}+v^{\prime}\left(g_{1}\right)\right)+\frac{\delta}{n_{1}}=0 \\
T_{1}: \quad \frac{u_{1}^{\prime}}{n_{1}}-\delta\left(\frac{1}{n_{1}}+\frac{1}{n_{2}}\right)=0
\end{gathered}
$$

where $\delta$ is the Lagrange multiplier associated with constraint (17). Combining these firstorder conditions, as well as those from the problem of region 2, we can show that regional policies will be such that $e_{1}=e_{2}, b^{\prime}\left(e_{1}\right)=b^{\prime}\left(e_{2}\right)=1+N d^{\prime}$, and $N v^{\prime}\left(g_{i}\right)=1$. Therefore, pollution policies are efficient, but regional public goods are over-provided relative to the optimum. There is a form of soft-budget constraint problem leading regions to choose their levels of public goods strategically in order to attract federal transfers.

The following proposition summarizes the main results of this section.

Under decentralized pollution control policy, the subgame perfect equilibrium has the following properties:

$i$. With imperfect labour mobility and federal transfers determined after regional policies, full efficiency is achieved: emissions in both regions and the allocation of population between regions are efficient (Caplan, Cornes and Silva, 2000);

ii. Without labour mobility, regional pollution policies are efficient and marginal utilities are equalized across regions by federal transfers, $u_{1}^{\prime}=u_{2}^{\prime}$;

iii. With perfect mobility, pollution policies are efficient without federal transfers, and federal transfers are neutral with respect to regional policies; and

iv. With perfect labour mobility and regional public goods, pollution policies, public good provision and the allocation of population are efficient without any need for federal transfers. If there are transfers, and they are determined after regional policies, pollution policies are efficient but public goods are over-provided. 


\section{Ex Ante Migration}

In this section, we reverse the timing of decisions, as in Mitsui and Sato (2001), by assuming that migration decisions are taken first followed by government policy decisions. The sequence of decisions is therefore as follows. First, individuals choose their region of residence. Second, regional governments choose $e_{i}$, and possibly $g_{i}$, given the population distribution and anticipating federal government transfers. Finally, the federal government chooses $T_{i}$. For reference purposes, note that Mitsui and Sato considered the case where regional governments provided a regional public good, the federal government made equalizing transfers, and households were perfectly mobile. They found that when households moved first anticipating federal equalization transfers, they would tend to agglomerate inefficiently across regions. This inefficiency could only be avoided if the federal government could commit to a transfer policy before households migrate. In our model with decentralized pollution control that benefits the residents of all regions, this inefficiency is avoided. Before characterizing the decentralized outcome, we briefly discuss the social optimum under this timing assumption.

\section{Social Optimum with Ex Ante Migration}

As in the previous section, we solve for the socially optimal regional and federal governments policies, with the allocation of labour across regions being determined by the migration equilibrium condition. Under the current timing assumption, when governments set their policies, migration decisions have already been taken. It is useful to distinguish between the cases where the migration equilibrium involves an interior solution with some individuals living in each region, and a corner solution where there is complete agglomeration of labour in one region. Consider first the case where there are some residents in each region. We characterize the social optimum by choosing the consumption of the clean and polluting goods in both regions to maximize the sum of utilities subject to the aggregate resource constraint, i.e.:

$$
\begin{gathered}
\max _{\left\{x_{i}, e_{i}\right\}} \quad n_{1} u\left(x_{1}+b\left(e_{1}\right)-d\left(n_{1} e_{1}+n_{2} e_{2}\right)\right)+\alpha n_{1} N-\int_{0}^{n_{1}} \alpha n d n \\
+n_{2} u\left(x_{2}+b\left(e_{2}\right)-d\left(n_{1} e_{1}+n_{2} e_{2}\right)\right)+\int_{n_{1}}^{N} \alpha n d n
\end{gathered}
$$


subject to

$$
n_{1} x_{1}+n_{2} x_{2}+n_{1} e_{1}+n_{2} e_{2}=F_{1}\left(n_{1}\right)+F_{2}\left(n_{2}\right)
$$

The problem is similar to the social optimum problem in the previous section, except that the allocation of population is taken as given. We can readily verify that the solution to this problem gives $u_{1}^{\prime}=u_{2}^{\prime}$ and $b^{\prime}\left(e_{1}\right)=b^{\prime}\left(e_{2}\right)=1+N d^{\prime}(\cdot)$, as in the case where migration decisions are assumed to be taken last. In turn, these conditions imply that $e_{1}=e_{2}$ and $x_{1}=x_{2}$. Therefore, residents in the two regions also have the same level of $u(\cdot)$.

Anticipating this allocation, individuals choose their region of residence in stage 1 . If there are some residents in each region, which is the case we are currently considering, it is straightforward to see that the population will be equally divided between the two regions, with the $N / 2$ individuals with $n \in[0, N / 2]$ residing in region 1 and the others residing in region 2. This is due to our assumption that the attachment-to-home parameter is uniformly distributed. Overall, the social optimum in this case is symmetric, even though $F_{1}(N / 2)$ may higher or lower than $F_{2}(N / 2)$.

Now, we consider the possibility of all individuals agglomerating in one region. For concreteness, suppose that $F_{1}(N)>F_{2}(N)$, so we only need to consider the possibility that all $N$ individuals reside in region 1 . In general, $F_{1}(N / 2)+F_{2}(N / 2)$ may be greater or less than $F_{1}(N)$. If the former is greater, the optimum will never involve complete agglomeration. The reason is the following. First, recall that $x_{1}=x_{2}$ and $e_{1}=e_{2}$ in the optimum where there are residents in each region. Then, if $F_{1}(N / 2)+F_{2}(N / 2) \geqslant F_{1}(N)$, there is more resources available in the non-agglomeration case, and so the optimum without complete agglomeration will necessarily involve a higher value of $u_{1}(\cdot)$ and $u_{2}(\cdot)$ than the optimum under complete agglomeration. Second, individuals with types $n$ in the range $[N / 2, N]$ will have a lower value of attachment-to-home in the agglomeration optimum than in the nonagglomeration optimum. Therefore, the optimum will not involve complete agglomeration if $F_{1}(N / 2)+F_{2}(N / 2) \geqslant F_{1}(N)$.

If instead $F_{1}(N / 2)+F_{2}(N / 2)<F_{1}(N)$, the maximized value of utility from consumption is higher if all individuals choose to reside in region 1 , but those with $n \in[N / 2, N]$ have lower attachment-to-home benefits than in the non-agglomeration case. Thus, the social 
optimum may or may not involve complete agglomeration in this case.

\section{Decentralized Pollution Control with Ex ante Migration}

Let us now characterize the decentralized outcome when migration decisions are taken before policy decisions. If the migration equilibrium involves complete agglomeration, there is obviously no need for interregional transfers and the pollution control policy in the single region that is populated will be efficient. More interestingly, if some individuals reside in each region, the federal government problem is essentially the same as in section 4, but without the migration constraint. The federal government chooses $T_{i}$, taking $e_{i}$ as given, to maximize the sum of utilities subject to each region's resource constraint and the federal budget constraint. It is straightforward to verify that the solution to this problem gives $u_{1}^{\prime}(\cdot)=u_{2}^{\prime}(\cdot)$.

Anticipating the federal government transfer policy, region 1 will choose its pollution control policy $e_{1}$ and (artificially) the federal transfer $T_{1}$ to maximize:

$$
u\left(\frac{F_{1}\left(n_{1}\right)+T_{1}-n_{1} e_{1}}{n_{1}}+b\left(e_{1}\right)-d\left(n_{1} e_{1}+n_{2} e_{2}\right)\right)
$$

subject to $u_{1}^{\prime}(\cdot)=u_{2}^{\prime}(\cdot)$. The attachment-to-home component is left out since population distribution is already fixed at this stage. For the same reason, maximizing total utility rather than per capita utility would lead to the same solution. Denoting by $\delta$ the Lagrange multiplier on the constraint characterizing the federal transfer policy, the first-order conditions are:

$$
\begin{gathered}
T_{1}: \quad \frac{u_{1}^{\prime}}{n_{1}}+\delta\left(\frac{u_{1}^{\prime \prime}}{n_{1}}+\frac{u_{2}^{\prime \prime}}{n_{2}}\right)=0 \\
e_{1}: \quad u_{1}^{\prime}\left(-1+b^{\prime}\left(e_{1}\right)-n_{1} d^{\prime}(\cdot)\right)+\delta\left(u_{1}^{\prime \prime}\left(-1+b^{\prime}\left(e_{1}\right)-n_{1} d^{\prime}(\cdot)\right)-u_{2}^{\prime \prime}\left(-n_{1} d(\cdot)\right)\right)=0
\end{gathered}
$$

To rearrange these conditions, note first that the federal transfer policy implies that $u_{1}^{\prime \prime}(\cdot)=$ $u_{2}^{\prime \prime}(\cdot)$. Using this, $(21)$ can be written as

$$
u_{1}^{\prime}=-\frac{N}{n_{2}} \delta u_{1}^{\prime \prime}
$$

Similarly, using $u_{1}^{\prime \prime}(\cdot)=u_{2}^{\prime \prime}(\cdot)$ in $(22)$ gives

$$
u_{1}^{\prime}\left(-1+b^{\prime}\left(e_{1}\right)-n_{1} d^{\prime}(\cdot)\right)+\delta u_{1}^{\prime \prime}\left(-1+b^{\prime}\left(e_{1}\right)\right)=0
$$


By substituting (23) into (24) and rearranging, we can recover the efficiency condition for $e_{1}$, i.e. $b^{\prime}\left(e_{1}\right)=1+N d^{\prime}(\cdot)$. Similarly, pollution policy in region 2 will be such that $b^{\prime}\left(e_{2}\right)=1+N d^{\prime}(\cdot)$. Thus, $e_{1}=e_{2}$, and since the federal transfer policy insures that $u_{1}=u_{2}$, we also have $x_{1}=x_{2}$.

Therefore, whether or not the migration equilibrium involves full agglomeration, decentralized pollution control will yield the social optimum.

\section{Decentralized Pollution Control with Ex ante Migration and Public Goods}

With regional public goods, the social optimum has the same properties as described above. In particular, pollution policies satisfy $b^{\prime}\left(e_{1}\right)=b^{\prime}\left(e_{2}\right)=1+N d^{\prime}(\cdot)$, which implies $e_{1}=e_{2}$. In addition, public goods provision will satisfy $n_{i} v^{\prime}\left(g_{i}\right)=1$. As before, the optimal transfer policy will insure that $u_{1}=u_{2}$. In turn, $u_{1}=u_{2}$ and $e_{1}=e_{2}$ imply that $x_{1}+v\left(g_{1}\right)=x_{2}+v\left(g_{2}\right)$. As in the absence of public goods, there may or may not be complete agglomeration. In the non-agglomeration case, the equilibrium is symmetric with $n_{1}=n_{2}=N / 2$ and $g_{1}=g_{2}$.

In the decentralized equilibrium, the federal transfer policy will be such that $u_{1}^{\prime}(\cdot)=u_{2}^{\prime}(\cdot)$. The government of region 1 will set its pollution control policy and its level of public good provision to maximize

$$
u\left(\frac{F_{1}\left(n_{1}\right)+T_{1}-n_{1} e_{1}-g_{1}}{n_{1}}+b\left(e_{1}\right)-d\left(n_{1} e_{1}+n_{2} e_{2}\right)+v\left(g_{1}\right)\right)
$$

subject to $u_{1}^{\prime}(\cdot)=u_{2}^{\prime}(\cdot)$. The first-order conditions on $T_{1}$ and $e_{1}$ have the same form as (21) and (22), implying that $e_{1}=e_{2}$ and $b^{\prime}\left(e_{i}\right)=1+N d^{\prime}(\cdot)$.

The first-order condition on $g_{1}$ is

$$
u_{1}^{\prime} \cdot\left(-\frac{1}{n_{1}}+v^{\prime}\left(g_{1}\right)\right)+\delta u_{1}^{\prime \prime} \cdot\left(-\frac{1}{n_{1}}+v^{\prime}\left(g_{1}\right)\right)=0
$$

which implies $n_{1} v^{\prime}\left(g_{1}\right)=1$. The same holds for region 2. The federal transfer policy implies that $u_{1}=u_{2}$, so in the non-agglomeration case $n_{1}=n_{2}=N / 2$ and $g_{1}=g_{2}$.

The main results of this section are outlined below.

When migration decisions are made before policy decisions, the allocation has the following properties: 
i. In the social optimum, individuals may or may not completely agglomerate in one region. If the non-agglomeration case, the outcome is symmetric even though regional production functions may be different. Both regions have the same levels of population, consumption of the clean good $x_{i}$, emissions $e_{i}$, and utilities $u(\cdot)$. If there are regional public goods, their provision levels will also be equalized; and

ii. Decentralized pollution control achieves full efficiency, with or without regional public goods and with or without complete population agglomeration.

\section{Voluntary Interregional Transfers}

We now return to the assumption that migration decisions are made last, and consider the case where regions can voluntarily provide transfers to each other, anticipating the impact on the allocation of population. This is the analogue of the case analyzed by Myers (1990) for a decentralized federation with regional public goods and perfect mobility. Myers showed that voluntary interregional transfers induce an efficient allocation of population across regions. We extend this analysis to the case where pollution abatement is a national public good and regions engage in emissions control policies. There are two stages. In the first stage, regions simultaneously choose their pollution policy and interregional transfer. Individuals then make their migration decisions in the second stage. There is no federal government. Let $T_{12}$ denote the transfer provided by region 1 to region 2 and $T_{21}$ region 2 's transfer to region 1 . Region 1 will therefore choose $e_{1}, n_{1}$ and $T_{12}$ to maximize

$$
n_{1} u\left(\frac{F_{1}\left(n_{1}\right)-n_{1} e_{1}-T_{12}+T_{21}}{n_{1}}+b\left(e_{1}\right)-d(\cdot)\right)+\alpha n_{1} N-\int_{0}^{n_{1}} \alpha n d n
$$

subject to the migration equilibrium condition,

$$
\begin{gathered}
u\left(\frac{F_{1}\left(n_{1}\right)-n_{1} e_{1}-T_{12}+T_{21}}{n_{1}}+b\left(e_{1}\right)-d(\cdot)\right)+\alpha\left(N-n_{1}\right) \\
\quad=u\left(\frac{F_{2}\left(n_{2}\right)-n_{2} e_{2}-T_{21}+T_{12}}{n_{2}}+b\left(e_{2}\right)-d(\cdot)\right)+\alpha n_{1}
\end{gathered}
$$

The first-order conditions are:

$$
e_{1}: \quad\left(n_{1}+\Phi\right) u_{1}^{\prime}\left(-1+b^{\prime}\left(e_{1}\right)-d^{\prime}(\cdot) n_{1}\right)+\Phi u_{2}^{\prime} d^{\prime}(\cdot) n_{1}=0
$$




$$
\begin{gathered}
T_{12}: \quad-\left(n_{1}+\Phi\right) \frac{u_{1}^{\prime}}{n_{1}}-\Phi \frac{u_{2}^{\prime}}{n_{2}}=0 \\
n_{1}: u_{1}+\left(n_{1}+\Phi\right) u_{1}^{\prime}\left(\frac{\left(F_{1}^{\prime}-e_{1}\right) n_{1}-\left(F_{1}\left(n_{1}\right)-n_{1} e_{1}-T_{12}+T_{21}\right)}{n_{1}^{2}}-d^{\prime}(\cdot)\left(e_{1}-e_{2}\right)\right) \\
+\alpha\left(N-n_{1}\right)-\Phi u_{2}^{\prime}\left(\frac{\left(-F_{2}^{\prime}+e_{2}\right) n_{2}+\left(F_{2}\left(n_{2}\right)-n_{2} e_{2}-T_{21}+T_{12}\right)}{n_{2}^{2}}\right. \\
\left.-d^{\prime}(\cdot)\left(e_{1}-e_{2}\right)\right)-2 \alpha \Phi=0
\end{gathered}
$$

Region 2 solves an analogous problem and the first-order conditions for the problems of both regions must be satisfied simultaneously. Combining the first-order conditions of both regions for their choice of pollution policy and transfer, we can derive the conditions that characterizes the socially optimal pollution policies, i.e. $b^{\prime}\left(e_{1}\right)=b^{\prime}\left(e_{2}\right)=1+N d^{\prime}(\cdot)$, which implies that $e_{1}=e_{2}$. Likewise, combining the regions' conditions for $n_{1}$ and for $n_{2}$, we can recover (8) which characterizes the optimal allocation of population. Therefore, the social optimum is achieved without a federal government. Note that full efficiency would also hold in this setting even in the presence of regional public goods. Hence, we have the following:

If regions can voluntarily provide transfers to each other, the socially optimal pollution policies and allocation of population across regions will be achieved without a federal government.

\section{Adding Public Goods Contributions}

In this section, we introduce a national public good financed by the voluntary contributions of regions. In contrast to Caplan, Cornes and Silva (2000), who have analyzed the case where regional governments voluntarily contribute to a national public good in the presence of labour mobility, we consider a setting with both contributions to a national public good and pollution control policies. Our interest is to examine the interaction between the two. We again assume that there is no federal government. Regions deploy pollution policies as well as contributing to the national public good. The timing of decisions is as follows. In the first stage, regions set their pollution policies $e_{i}$ which are viewed as longer-run decisions 
than contributions to the public good. In the second stage, regions simultaneously choose their contributions to the national public good. Finally, individuals make their migration decisions. The utility function must now include the benefits from the national public good and is assumed to take the following form: $u\left(x_{i}+b\left(e_{i}\right)-d(\cdot)+v\left(g_{1}+g_{2}\right)\right)$, with $v^{\prime}\left(g_{1}+g_{2}\right)>0$ and $v^{\prime \prime}\left(g_{1}+g_{2}\right)<0$, where $g_{i}$ denotes the public good contribution of region $i$.

It is useful to start with the special case where there is no migration.

\section{Public Good Contributions}

Given $e_{i}$, regions simultaneously choose their contributions to the national public good. The problem of region 1 is to set $g_{1}$ and $x_{1}$ to maximize $u\left(x_{1}+b\left(e_{1}\right)-d\left(n_{1} e_{1}+n_{2} e_{2}\right)+\right.$ $\left.v\left(g_{1}+g_{2}\right)\right)$, subject to its resource constraint, $n_{1} x_{1}=F\left(n_{1}\right)-n_{1} e_{1}-g_{1}$. Following the methodology used by Bergstrom, Blume and Varian (1986), it is convenient to rewrite this problem as follows:

$$
\max _{\left\{X_{1}, g_{i}\right\}} u\left(\frac{X_{1}}{n_{1}}+v\left(g_{1}+g_{2}\right)\right) \quad \text { s.t. } \quad X_{1}+g_{1}=F\left(n_{1}\right)+I_{1}
$$

where $X_{1} \equiv n_{1} x_{1}+n_{1} b\left(e_{1}\right)-n_{1} d\left(n_{1} e_{1}+n_{2} e_{2}\right)$ is consumption of the private good and net-of-externality emissions, and $I_{1} \equiv n_{1} b\left(e_{1}\right)-n_{1} e_{1}-n_{1} d\left(n_{1} e_{1}+n_{2} e_{2}\right)$ is the benefit of emissions net of the costs. Region 2 solves an analogous problem. With the regional problem written this way, we can readily verify that the Neutrality Theorem (Shibata 1971, Warr 1983) implies that $X_{1}, X_{2}$ and $G=g_{1}+g_{2}$ depend only on aggregate national 'wealth', which can be defined in this context as $F\left(n_{1}\right)+F\left(n_{2}\right)+I_{1}+I_{2}$. Given this, the utility of region 1 in the second stage can be written as

$$
u\left(\frac{X_{1}\left(F\left(n_{1}\right)+F\left(n_{2}\right)+I_{1}+I_{2}\right)}{n_{1}}+v\left(G\left(F\left(n_{1}\right)+F\left(n_{2}\right)+I_{1}+I_{2}\right)\right)\right)
$$

and similarly for region 2 .

\section{Pollution Policies}

Anticipating the equilibrium in public good contributions, each region will set its level of emissions to maximize utility. Given that utility takes the form shown above, each region 
will, in effect, maximize $u(\cdot)$ by maximizing $I_{1}+I_{2}$, where

$$
I_{1}+I_{2}=n_{1} b\left(e_{1}\right)-n_{1} e_{1}+n_{2} b\left(e_{2}\right)-n_{2} e_{2}-N d\left(n_{1} e_{1}+n_{2} e_{2}\right)
$$

Maximizing this with respect to $e_{i}$ immediately leads to $b^{\prime}\left(e_{i}\right)=1+N d^{\prime}(\cdot)$ for $i=1,2$, so pollution control policies are efficient. However, provision of the public good remains inefficiently low as in standard voluntary contributions models.

Perfect labour mobility in the current setting would play the same role as in the case considered in Section 4. Labour mobility in the last stage would equalize utilities across regions. Anticipating this, regional governments would choose their pollution policies and public good contributions to maximize the common level of utility. So the incentives of both regions would be perfectly aligned and the equilibrium would be efficient.

This would not hold however with imperfect labour mobility. In this case, utilities would not be fully equalized. Furthermore, the Neutrality Theorem would not apply for public good contributions since regions would take into account the effect of their contribution on the allocation of population, unless regions are assumed to behave myopically with respect to migration.

This is summarized in the following.

In the presence of a national public good provided by the voluntary contributions of regions, pollution policies are efficient without labour mobility and without a federal government, as long as pollution policies are set first followed by contributions to the national public good.

\section{Regional Commitment: Matching Abatements}

We now consider a case where regions can voluntarily offer to match the emission reduction effort of the other region. We assume that region $i$ can commit to match the emission reduction of region $j$ at rate $m_{i}$. Let $\bar{e}_{i}$ denote the per capita emissions that region $i$ would choose in the absence of any matching commitment, and $\hat{e}_{i}$ the per capita emission target of region $i$, before matching the abatements of the other region. Then, the actual per capita emissions in region $i$ will be equal to $e_{i}=\hat{e}_{i}-m_{i}\left(\bar{e}_{j}-\hat{e}_{j}\right)$ and the emissions 
reduction will be $\bar{e}_{i}-e_{i}$. The mechanism involves two stages. In the first stage, regions simultaneously choose matching rates $m_{i}$, anticipating the effect of their matching rate on the emission target chosen by the other region. In the second stage, given $m_{i}$, regions simultaneously choose emission targets $\hat{e}_{i} \cdot{ }^{3}$ We continue to assume that there is no federal government and no labour mobility.

\section{Efficient Pollution Control}

Before characterizing the equilibrium pollution policies under this mechanism, it is useful to distinguish between two notions of efficiency, one with and the other without interregional transfers, following Sandmo (2006). In the absence of transfers, we can characterize efficient emissions by solving the following Pareto-optimizing problem:

$$
\begin{array}{ll}
\max _{e_{1}, e_{2}} & u\left(\frac{F_{1}\left(n_{1}\right)-n_{1} e_{1}}{n_{1}}+b\left(e_{1}\right)-d\left(n_{1} e_{1}+n_{2} e_{2}\right)\right) \\
\text { s.t. } & u\left(\frac{F_{2}\left(n_{2}\right)-n_{2} e_{2}}{n_{2}}+b\left(e_{2}\right)-d\left(n_{1} e_{1}+n_{2} e_{2}\right)\right) \geqslant \overline{u_{2}}
\end{array}
$$

where $\overline{u_{2}}$ is some exogenous level of utility in region 2 . The first-order conditions to this problem yield:

$$
\frac{n_{1} d^{\prime}(\cdot)}{b^{\prime}\left(e_{1}\right)-1}+\frac{n_{2} d^{\prime}(\cdot)}{b^{\prime}\left(e_{2}\right)-1}=1
$$

This condition says that the sum of ratios of marginal damages to marginal benefits (net of the cost of the polluting good) will equal unity. This is analogous to a Samuelson condition in the current context. Generally, $b^{\prime}\left(e_{1}\right) \neq b^{\prime}\left(e_{2}\right)$, so the pollution policies characterized by (28) are constrained efficient.

With interregional transfers, the Pareto-optimizing problem becomes the following:

$$
\begin{gathered}
\max _{e_{1}, e_{2}, T} u\left(\frac{F_{1}\left(n_{1}\right)+T-n_{1} e_{1}}{n_{1}}+b\left(e_{1}\right)-d\left(n_{1} e_{1}+n_{2} e_{2}\right)\right) \\
\text { s.t. } \quad u\left(\frac{F_{2}\left(n_{2}\right)-T-n_{2} e_{2}}{n_{2}}+b\left(e_{2}\right)-d\left(n_{1} e_{1}+n_{2} e_{2}\right)\right) \geqslant \overline{u_{2}}
\end{gathered}
$$

3 This mechanism is also analyzed in a similar setting by Boadway, Song and Tremblay (2011), and in the context of voluntary contributions to an international public good by Boadway, Song and Tremblay (2007). Matching contributions mechanisms have also been analyzed in Guttman (1978), Danziger and Schnytzer (1991), Althammer and Buchholz (1993), Varian (1994) and Buchholz, Cornes and Rübbelke (2011, 2012), among others. 
In this case, the first-order conditions lead to $(24)$ and $b^{\prime}\left(e_{1}\right)=b^{\prime}\left(e_{2}\right)$. Combining these yields $b^{\prime}\left(e_{1}\right)=b^{\prime}\left(e_{2}\right)=1+N d^{\prime}(\cdot)$, so full efficiency is achieved: the marginal benefits of emissions are equalized across regions, and are equal to the relative price of the polluting good plus the sum of marginal damages.

\section{Matching Abatements: Stage 2}

Let us now turn to the mechanism defined above. We start by deriving the choice of emission targets in the second stage before characterizing the subgame perfect equilibrium matching rates chosen by regions in the first stage. In Stage 2 , given $\left(m_{1}, m_{2}\right)$, region 1 chooses $\hat{e}_{1}$ to maximize the following:

$$
\begin{aligned}
& u\left(\frac{F_{1}\left(n_{1}\right)}{n_{1}}-\left(\hat{e}_{1}-m_{1}\left(\bar{e}_{2}-\hat{e}_{2}\right)\right)+b\left(\hat{e}_{1}-m_{1}\left(\bar{e}_{2}-\hat{e}_{2}\right)\right)\right. \\
& \left.\quad-d\left(n_{1}\left(\hat{e}_{1}-m_{1}\left(\bar{e}_{2}-\hat{e}_{2}\right)\right)+n_{2}\left(\hat{e}_{2}-m_{2}\left(\bar{e}_{1}-\hat{e}_{1}\right)\right)\right)\right)
\end{aligned}
$$

and similarly, for region 2. Assuming an interior solution, the first-order conditions for both regions give:

$$
\frac{n_{1} d^{\prime}(\cdot)}{b_{1}^{\prime}\left(e_{1}\right)-1}=\frac{1}{1+m_{2}}, \quad \frac{n_{2} d^{\prime}(\cdot)}{b_{2}^{\prime}\left(e_{2}\right)-1}=\frac{1}{1+m_{1}}
$$

Regions choose their emission target such that the ratio of marginal damages to net marginal benefits equals the effective per capita cost of reducing emissions by one unit, given the matching rate offered by the other region. The equations in (29) are the reaction functions of each region. In equilibrium, both reaction functions must be satisfied simultaneously to yield the Nash equilibrium emissions $e_{1}\left(m_{1}, m_{2}\right)$ and $e_{2}\left(m_{1}, m_{2}\right)$.

\section{Matching Abatements: Stage 1}

In Stage 1, both regions choose their matching rates simultaneously, anticipating the Nash equilibrium in Stage 2. The derivation of the equilibrium is analogous to that presented in a similar setting in Boadway, Song and Tremblay (2011). Therefore, we will simply outline the main properties of the equilibrium without going into formal demonstrations.

The slopes of each region's reaction curve in Stage 2 will depend on the matching rates chosen in Stage 1. In the space where we have the emission reduction of each region on the 
two axis, we can show that both regions' reaction curves will be linear and parallel if the matching rates are such that $m_{1} m_{2}=1$, or equivalently, when the matching rates are the reciprocals of each other. Moreover, for unique values of $m_{1}$ and $m_{2}$ satisfying $m_{1} m_{2}=1$, the reaction curves will coincide. In fact, these will be the subgame perfect equilibrium matching rates.

To build some simple intuition for this result, it is useful to note the following. First, when $m_{1} m_{2}=1$ and the Stage 2 reaction curves coincide, direct emissions $\left(\hat{e}_{1}, \hat{e}_{2}\right)$ are indeterminate, but total emissions $\left(e_{1}, e_{2}\right)$ are uniquely determined. This implies that along the common reaction curve, the utility levels of each region are constant. Second, when matching rates satisfy $m_{1} m_{2}=1$, regions are indifferent between direct and indirect (or matching) emission reductions. To see this, note that the cost for region 1 of reducing emissions by one unit directly (i.e. by reducing its own emission target $\hat{e_{1}}$ ) is equal to $1 /\left(1+m_{2}\right)$. On the other hand, the cost of reducing emissions by one unit indirectly (i.e. by matching the emission reduction of the other region) is $m_{1} /\left(1+m_{1}\right) .{ }^{4}$ When $m_{1} m_{2}=1$, we have $1 /\left(1+m_{2}\right)=m_{1} /\left(1+m_{1}\right)$, so the direct and indirect costs of reducing emissions faced by region 1 are equal. The same applies for region 2. Neither region has any incentive to deviate from such an allocation, so the matching rates for which $m_{1} m_{2}=1$ and reaction curves coincide constitute a subgame perfect equilibrium. Intuitively, starting from any point on the common reaction curve with $m_{1} m_{2}=1$, if one region were to increase its matching rate, it would end up reducing emissions indirectly at a cost higher than the cost of reducing emissions directly. Therefore, there would be no incentive to do so. Similarly, if one region were to reduce its matching rate, it would then be reducing emissions directly at a cost higher than the indirect cost of emission reduction.

Two properties of this equilibrium are particularly interesting. First, using (29) and

4 Total emissions reduction by both regions is equal to $\left(\bar{e}_{1}-e_{1}\right)+\left(\bar{e}_{2}-e_{2}\right)=\bar{e}_{1}-\hat{e}_{1}+m_{1}\left(\bar{e}_{2}-\right.$ $\left.\hat{e}_{2}\right)+\bar{e}_{2}-\hat{e}_{2}+m_{2}\left(\bar{e}_{1}-\hat{e}_{1}\right)=\left(1+m_{2}\right)\left(\bar{e}_{1}-\hat{e}_{1}\right)+\left(1+m_{1}\right)\left(\bar{e}_{2}-\hat{e}_{2}\right)$. A reduction of $\hat{e}_{2}$ by $\Delta \hat{e}_{2}=1 /\left(1+m_{1}\right)$ will lower total emissions by one unit. The change of $\hat{e}_{2}$ will be matched by region 1 at rate $m_{1}$, so will cost $m_{1} /\left(1+m_{1}\right)$ to region 1 . 
$m_{1} m_{2}=1$, we can readily show that

$$
\frac{n_{1} d^{\prime}(\cdot)}{b^{\prime}\left(e_{1}\right)-1}+\frac{n_{2} d^{\prime}(\cdot)}{b^{\prime}\left(e_{2}\right)-1}=1
$$

so the levels of emissions are constrained efficient. Second, the effective cost of emission reduction faced by each country is the analogue of a Lindahl price. To see this, we can multiply the direct cost of emission reduction faced by region 1 , i.e. $1 /\left(1+m_{2}\right)$, by the total emission reduction of both regions, and we obtain the total direct and matching emission reduction of region 1 :

$$
\begin{gathered}
\frac{1}{1+m_{2}}\left(\bar{e}_{1}-e_{1}+\bar{e}_{2}-e_{2}\right)=\frac{1}{1+m_{2}}\left(\bar{e}_{1}-\hat{e_{1}}+m_{1}\left(\bar{e}_{2}-\hat{e_{2}}\right)+\bar{e}_{2}-\hat{e_{2}}+m_{2}\left(\bar{e}_{1}-\hat{e_{1}}\right)\right) \\
=\bar{e}_{1}-\hat{e_{1}}+m_{1}\left(\bar{e}_{2}-\hat{e_{2}}\right)
\end{gathered}
$$

where we have used $m_{2}=1 / m_{1}$. The cost of emission reduction faced by region 1 is therefore the price at which region 1 would be willing to provide the total emission abatement of both regions, so it can be seen as a Lindahl price.

\section{Matching Abatements with Emissions Quota Trading}

We now add a third stage to the mechanism to let regions trade emissions quotas on a competitive market. The first two stages are as before and they essentially determine the emission quota to which each region commits. Let $q_{i}$ denote the demand for quotas in the third stage by region $i$, with $q_{i} \gtreqless 0$. The market price of quotas $p$ is determined by the market clearing condition $\sum_{i} q_{i}(p)=0$. We assume that regions take the price of quotas as given. The timing of decisions is now as follows. In Stage 1, regions simultaneously choose $m_{i}$. Given $\left(m_{1}, m_{2}\right)$, regions choose $\hat{e}_{i}$ in the second stage. Finally, in Stage 3, given $\left(\hat{e}_{1}, \hat{e}_{2}\right)$ (as well as $\left(e_{1}, e_{2}\right)$ ), regions choose their demand for quotas $q_{i}$.

Assuming an interior solution, the demand for quotas by region i will maximize:

$$
u\left(F\left(n_{i}\right) / n_{i}-e_{i}-p q_{i} / n_{i}+b\left(e_{i}+q_{i} / n_{i}\right)-d(\cdot)\right)
$$

where the actual emissions of region $i$ are now $e_{i}+\left(q_{i} / n_{i}\right)=\hat{e}_{i}-m_{i}\left(\bar{e}_{j}-\hat{e}_{j}\right)+\left(q_{i} / n_{i}\right)$. Solving this problem for both regions gives $b_{1}^{\prime}(\cdot)=b_{2}^{\prime}(\cdot)=p$. Quota trading leads to an equalization of the marginal benefits of the polluting good across regions. 
With quota trading, the choice of emission target by region 1 in Stage 2 will maximize the following:

$$
\begin{aligned}
& u\left(\frac{F_{1}\left(n_{1}\right)}{n_{1}}-\left(\hat{e}_{1}-m_{1}\left(\bar{e}_{2}-\hat{e}_{2}\right)\right)-\frac{p q_{1}}{n_{1}}+b\left(\hat{e}_{1}-m_{1}\left(\bar{e}_{2}-\hat{e}_{2}\right)+\frac{q_{1}}{n_{1}}\right)\right. \\
& \left.\quad-d\left(n_{1}\left(\hat{e}_{1}-m_{1}\left(\bar{e}_{2}-\hat{e}_{2}\right)+\frac{q_{1}}{n_{1}}\right)+n_{2}\left(\hat{e}_{2}-m_{2}\left(\bar{e}_{1}-\hat{e}_{1}\right)+\frac{q_{2}}{n_{2}}\right)\right)\right)
\end{aligned}
$$

When solving this problem, the regional government anticipates the equilibrium price of quotas that will be determined in the following stage. The problem of region 2 is analog and is solved simultaneously. It is easy to verify that the solutions to these problems will give (29). Moreover, the subgame perfect equilibrium matching rates will again be such that $m_{1} m_{2}=1$ and that both regional reaction curves in Stage 2 coincide. In fact, the equilibrium will have the same properties as in the case without quota trading, although in this case, the marginal benefits of emission will be equalized across regions, so full efficiency is achieved, i.e. $b^{\prime}\left(e_{1}\right)=b^{\prime}\left(e_{2}\right)=1+N d^{\prime}(\cdot)$, and Lindahl pricing holds.

The results of this section are outlined in the following proposition.

When regions can commit to match the pollution reduction efforts of each other, the subgame perfect equilibrium has the following properties:

i. Efficient pollution control policies are achieved without labour mobility and without a federal government;

ii. Without emission quota trading, emissions are constrained efficient: the sum of ratios of marginal damages to marginal benefits equals unity, but the marginal benefits of emissions are not equalized across regions, $b^{\prime}\left(e_{1}\right) \neq b^{\prime}\left(e_{2}\right)$;

iii. With quota trading, the equilibrium is fully efficient: the marginal benefits of emissions equal the relative cost of the polluting good plus the sum of marginal damages, and are equal in both regions; 
iv. Matching rates are such that, for each region, the direct cost of reducing emissions equals the indirect (matching) cost; and

v. In equilibrium, the effective cost of reducing emissions for each region is the analogue of a Lindahl price.

\section{Regional Commitment: Stackelberg Leader}

In this section, we consider a different form of commitment. We assume that one region, say region 1, is a Stackelberg leader so can commit to a specific level of emission reduction, anticipating the response of the other region. Moreover, we assume that region 1 exploits is ability to commit to the fullest. Rather than simply taking as given how region 2 will react, as in a standard Stackelberg model, it makes its emission reduction contingent on region 2's emissions not exceeding some specified maximum level. We refer to this as a quantity contingent mechanism $(\mathrm{QCM}) .{ }^{5}$ We continue to assume that there is no federal government and no labour mobility.

The mechanism involves three stages. In the first stage, region 1 commits to a level of emissions $\tilde{e}_{1}$ and a transfer $\widetilde{T}_{12}$ to region 2 if the emissions of region 2 are not higher than $\tilde{e}_{2}$. If region 2 exceeds this maximum, region 1 commits to some level of emissions $\bar{e}_{1} \geqslant 0$ and transfer $T_{12}=0$, where $\bar{e}_{1}$ is exogenous and can be seen as the business-asusual emissions level. In Stage 2, region 2 chooses its level of emissions $e_{2}$, given region 1's announced commitment. In the last stage, region 1 chooses $e_{1}$ and $T_{12}$ according to its previous commitment. Again, the equilibrium is solved by backward induction starting with second stage.

\section{Stage 2}

At this stage, given the values of $\tilde{e}_{1}, \widetilde{T}_{12}$ and $\bar{e}_{1}$ announced by region 1 , region 2 chooses $e_{2}=\tilde{e}_{2}$ if

$$
u\left(\frac{F_{2}\left(n_{2}\right)+\widetilde{T}_{12}}{n_{2}}-\tilde{e}_{2}+b\left(\tilde{e}_{2}\right)-d\left(n_{1} \tilde{e}_{1}+n_{2} \tilde{e}_{2}\right)\right) \geqslant \bar{u}_{2}
$$

5 Boadway, Song and Tremblay (2007) have analyzed a similar mechanism in the context of voluntary contributions to an international public good. 
where

$$
\bar{u}_{2}=\max _{\left\{e_{2}\right\}} u\left(\frac{F\left(n_{2}\right)}{n_{2}}-e_{2}+b\left(e_{2}\right)-d\left(n_{1} \bar{e}_{1}+n_{2} e_{2}\right)\right)
$$

That is, if region 2 chooses not to satisfy the requirement of the QCM, it simply sets its emissions level to maximize utility.

\section{Stage 1}

In the first stage, region 1 will anticipate region 2's decision and will set the QCM parameters to induce compliance by region 2 . The problem is the following:

$$
\max _{\tilde{e}_{1}, \tilde{e}_{2}, \widetilde{T}_{12}} u\left(\frac{F_{1}\left(n_{1}\right)-\widetilde{T}_{12}}{n_{1}}-\tilde{e}_{1}+b\left(\tilde{e}_{1}\right)-d\left(n_{1} \tilde{e}_{1}+n_{2} \tilde{e}_{2}\right)\right)
$$

subject to (30). The first-order conditions to this problem are:

$$
\begin{gathered}
\tilde{e}_{1}: \quad u_{1}^{\prime}\left(-1+b^{\prime}\left(\tilde{e}_{1}\right)-n_{1} d^{\prime}(\cdot)\right)+\lambda u_{2}^{\prime} n_{1} d^{\prime}(\cdot)=0 \\
\tilde{e}_{2}: \quad-u_{1}^{\prime} n_{2} d^{\prime}(\cdot)+\lambda u_{2}^{\prime}\left(-1+b^{\prime}\left(\tilde{e}_{2}\right)-n_{2} d^{\prime}(\cdot)\right)=0 \\
\widetilde{T}_{12}: \quad-\frac{u_{1}^{\prime}}{n_{1}}-\frac{\lambda u_{2}^{\prime}}{n_{2}}=0
\end{gathered}
$$

By combining these conditions, we can readily verify that $b^{\prime}\left(\tilde{e}_{1}\right)=b^{\prime}\left(\tilde{e}_{2}\right)=1+N d^{\prime}(\cdot)$, so full efficiency is achieved. This is not surprising since region 1's problem is equivalent to a Pareto-maximizing problem. Solving that problem maximizes the surplus available for the region.

If the QCM does not include a transfer, then the problems of both regions are the same as above, but with $\widetilde{T}_{12}=0$. The first-order conditions are simply (31) and (32), and combining them yields equation (28). Therefore, without interregional transfers, the outcome is constrained efficient.

\section{Quantity Contingent Mechanism with Labour Mobility}

Finally, let us briefly examine the outcome of the QCM with mobile labour. In this case, assuming that region 2 maximizes the sum of utilities of its final residents, it will comply with the QCM if

$$
n_{2} u\left(\frac{F_{2}\left(n_{2}\right)+\widetilde{T}_{12}}{n_{2}}-\tilde{e}_{2}+b\left(\tilde{e}_{2}\right)-d\left(n_{1} \tilde{e}_{1}+n_{2} \tilde{e}_{2}\right)\right)+\int_{n_{1}}^{N} \alpha n d n \geqslant \bar{u}_{2}
$$


where $\bar{u}_{2}$ maximizes total utility, including the sum of attachment benefits, given region 1 's policies in the absence of compliance, i.e.

$$
\bar{u}_{2}=\max _{\left\{e_{2}\right\}} n_{2} u\left(\frac{F\left(n_{2}\right)}{n_{2}}-e_{2}+b\left(e_{2}\right)-d\left(n_{1} \bar{e}_{1}+n_{2} e_{2}\right)\right)+\int_{n_{1}}^{N} \alpha n d n
$$

In the first stage, region 1 will choose the parameters of the $\operatorname{QCM}\left(\tilde{e}_{1}, \tilde{e}_{2}, \widetilde{T}_{12}\right)$, as well as $n_{1}$ (artificially) to maximize

$$
n_{1} u\left(\frac{F_{1}\left(n_{1}\right)-\widetilde{T}_{12}}{n_{1}}-\tilde{e}_{1}+b\left(\tilde{e}_{1}\right)-d\left(n_{1} \tilde{e}_{1}+n_{2} \tilde{e}_{2}\right)\right)+\alpha n_{1} N-\int_{0}^{n_{1}} \alpha n d n
$$

subject to (34) and the migration equilibrium condition:

$$
\begin{aligned}
& u\left(\frac{F_{1}\left(n_{1}\right)-\widetilde{T}_{12}}{n_{1}}-\tilde{e}_{1}+b\left(\tilde{e}_{1}\right)-d\left(n_{1} \tilde{e}_{1}+n_{2} \tilde{e}_{2}\right)\right)+\alpha\left(N-n_{1}\right) \\
& =u\left(\frac{F_{2}\left(n_{2}\right)+\widetilde{T}_{12}}{n_{2}}-\tilde{e}_{2}+b\left(\tilde{e}_{2}\right)-d\left(n_{1} \tilde{e}_{1}+n_{2} \tilde{e}_{2}\right)\right)+\alpha n_{1}
\end{aligned}
$$

When the QCM includes a transfer, one can show from the first-order conditions to this problem that emissions in each region are such that $b^{\prime}\left(\tilde{e}_{1}\right)=b^{\prime}\left(\tilde{e}_{2}\right)=1+N d^{\prime}(\cdot)$. That is, pollution policies are fully efficient even with imperfectly mobile labour. However, the allocation of population across regions will not be efficient since region 1, which is acting as the leader, will have incentives to set the QCM so as to attract labour.

The analysis of this section is summarized in the following proposition.

When one region can commit to a particular level of emissions contingent on the emissions of the other region being no more than some specified level, the equilibrium satisfies the following:

i. Pollution control policies are fully efficient, i.e. $b^{\prime}\left(\tilde{e}_{1}\right)=b^{\prime}\left(\tilde{e}_{2}\right)=1+N d^{\prime}(\cdot)$, without a federal government if the QCM set by the leader can include an interregional transfer;

ii. If the leader cannot commit to a transfer as part of the QCM, pollution policies are constrained efficient; and

iii. With imperfect labour mobility, pollution policies remain fully efficient if the QCM includes a transfer (and constrained efficient if not), but the allocation of population across regions is not efficient. 


\section{Conclusions}

This paper has characterized decentralized pollution control policies in different settings. The analysis has shown that, even when regional governments behave non-cooperatively, efficient outcomes can arise under various circumstances. When regions set their pollution policies first, anticipating how federal transfers and individual migration decisions will respond, the levels of emissions will be efficient as well as the allocation of population across regions, even if labour is imperfectly mobile. Efficiency will also hold if migration decisions are taken before policy decisions. If labour mobility is perfect, efficiency will hold even in the absence of federal transfers and even if regions are also providing regional public goods. Efficiency will also be achieved with imperfect labour mobility and in the absence of a federal government, provided that regions can make voluntary transfers to each other. When regions voluntarily contribute to a national public good after setting their pollution control policies, emissions will be efficient in the absence of a federal government and without labour mobility, although the national public good will be under-provided. Finally, if regions can commit to matching the emission abatements of each other, or if one region can commit to a particular level of emissions contingent on the emissions of the other region not exceeding some specific level, pollution policies will also be efficient without a federal government and labour mobility.

A number of extensions to the analysis could be considered. In particular, some of the cases considered could be extended to multi-period settings where damage functions would depend on the accumulation of emissions over time. We could also explore whether the various efficiency results would hold if the emissions of each region were imperfect substitutes in damage functions.

\section{References}

Akai, Nobuo and Motohiro Sato (2008), 'Too Big or Too Small? A Synthetic View of the Commitment Problem of Interregional Transfers', Journal of Urban Economics 64, $551-559$. 
Althammer, Wilhelm and Wolfgang Buchholz (1993), 'Lindahl-equilibria as the Outcome of a Non-cooperative Game', European Journal of Political Economy 9, 399-405.

Altemeyer-Bartscher, Martin, Dirk T.G. Rübbelke and Eytan Sheshinski (2010), 'Environmental Protection and the Private Provision of International Public Goods', Economica $77,775-84$.

Bergstrom, Theodore, Lawrence Blume and Hal Varian (1986), 'On the Private Provision of Public Goods', Journal of Public Economics 29, 25-49.

Boadway, Robin (1982), 'On the Method of Taxation and the Provision of Local Public Goods: Comment,' American Economic Review 72, 846-51.

Boadway, Robin and Frank Flatters (1982), 'Efficiency and Equalization Payments in a Federal System of Government: a Synthesis and Extension of Recent Results', Canadian Journal of Economics 15, 613-33.

Boadway, Robin and Masayoshi Hayashi (1999), 'Country Size and the Voluntary Provision of International Public Goods', European Journal of Political Economy 15, 619-38.

Boadway, Robin and Jean-François Tremblay (2006), 'A Theory of Fiscal Imbalance', FinanzArchiv 62, 1-27.

Boadway, Robin, Zhen Song and Jean-François Tremblay (2007), 'Commitment and Matching Contributions to Public Goods', Journal of Public Economics 91, 1664-83.

Boadway, Robin, Zhen Song and Jean-François Tremblay (2011), 'The Efficiency of Voluntary Pollution Abatement when Countries can Commit', European Journal of Political Economy 27, 352-68.

Breuillé, Marie-Laure and Marianne Vigneault (2010), 'Overlapping Soft Budget Constraints', Journal of Urban Economics, 67, 259-69.

Buchanan, James M., and Charles Goetz (1972), 'Efficiency Limits of Fiscal Mobility: An Assessment of the Tiebout Model', Journal of Public Economics 1, 25-43. 
Buchholz, Wolfgang, Richard Cornes and Dirk Rübbelke (2011), 'Interior Matching Equilibria in a Public Good Economy: An Aggregative Game Approach', Journal of Public Economics 95, 639-645.

Buchholz, Wolfgang, Richard Cornes and Dirk Rübbelke (2012), 'Potentially Harmful International Cooperation on Global Public Good Provision', CESifo Working Paper, no. 3891.

Caplan, Arthur J., Richard C. Cornes and Emilson C. Silva (2000), 'Pure Public Goods and Income Redistribution in a Federation with Decentralized Leadership and Imperfect Labor Mobility', Journal of Public Economics 77, 265-284.

Danziger, Leif and Adi Schnytzer (1991), 'Implementing the Lindahl Voluntary-Exchange Mechanism', European Journal of Political Economy 7, 55-64.

Flatters, Frank, Vernon Henderson and Peter Mieszkowski (1974), 'Public Goods, Efficiency, and Regional Fiscal Equalisation', Journal of Public Economics 3, 99-112.

Gerber, Anka and Philipp C. Wichardt (2009), 'Providing Public Goods in the Absence of Strong Institutions', Journal of Public Economics 93, 429-39.

Gersbach, Hans and Ralph Winkler (2007), 'On the Design of Global Refunding and Climate Change; Working Paper no. 07/69, Center of Economic Research, ETH Zurich.

Goodspeed, Timothy J. (2002), 'Bailouts in a Federation', International Tax and Public Finance 9, 409-21.

Guttman, Joel (1978), 'Understanding Collective Action: Matching Behavior', American Economic Review 68, 251-55.

Guttman, Joel and Adi Schnytzer (1992), 'A Solution of the Externality Problem Using Strategic Matching', Social Choice and Welfare 8, 73-88.

Mansoorian, Arman and Gordon M. Myers (1993), 'Attachment to Home and Efficient 
Purchases of Population in a Fiscal Externality Economy', Journal of Public Economics 52, $117-32$.

Mitsui, Kiyoshi and Motohiro Sato (2001), 'Ex Ante Free Mobility, Ex Post Immobility, and Time-Consistent Policy in a Federal System', Journal of Public Economics 82, 445-60.

Myers, Gordon M. (1990), 'Optimality, Free Mobility and Regional Authority in a Federation', Journal of Public Economics 43, 107-21.

Myers, Gordon M. and Yorgos Y. Papageorgiou (1993), 'Fiscal Inequivalence, Incentive Equivalence and Pareto Efficiency in a Decentralized Urban Context', Journal of Urban Economics 33, 29-47.

Sandmo, Agnar (2006), 'Global Public Economics: Public Goods and Externalities', Économie Publique/Public Economics 18-19, 57-75.

Shibata, Hirofumi (1971), 'A Bargaining Model of the Pure Theory of Public Expenditure', Journal of Political Economy 79, 1-29.

Silva, Emilson C. and Arthur J. Caplan (1997), 'Transboundary Pollution Control in Federal Systems', Journal of Environmental Economics and Management 34, 173-86.

Varian, Hal (1994), 'Sequential Contributions to Public Goods', Journal of Public Economics 53, 165-86.

Warr, Peter (1983), 'The Private Production of a Public Good is Independent of the Distribution of Income', Economic Letters 13, 207-11.

Wildasin, David E. (2004), 'The Institutions of Federalism: Toward an Analytical Approach', National Tax Journal 57, 247-72.

Wrede, Matthias (1998), 'Household Mobility and the Moderate Leviathan Efficiency and Decentralization', Regional Science and Urban Economics 28, 315-28. 